\title{
Liming alters body size distribution in a community of epigeic spiders in birch forest (Betula pendula Roth)
}

\author{
Radek Michalko ${ }^{1} \cdot$ Emanuel Kula $^{2} \cdot$ Ondřej Košulič $^{2}$
}

Received: 15 March 2018 / Accepted: 5 September 2018 / Published online: 5 November 2018

(C) INRA and Springer-Verlag France SAS, part of Springer Nature 2018

\begin{abstract} altering the soil characteristics and/or the availability of food resources. characteristics, effect of liming on birch, and densities of potential prey. decreased the densities of spiders' preferred prey. preferred prey.

\section{Handling Editor: Aurélien Sallé}

Contribution of the co-authors Radek Michalko contributed to the determination of spiders, analyzed the data, and wrote the manuscript. Emanuel Kula conceived the idea, designed the study, and performed the field work. Ondřej Košulič participated on the determination of spiders. All authors read, commented, and approved the submission of the manuscript.
\end{abstract}

- Key message Liming, an ameliorative method for acidified forest soils, affected the relative abundance of prey of ground-hunting spiders and consequently reduced densities of functionally similar species of these predators.

- Context Liming, an ameliorative method for acidified forest soils, may modify the structure of an arthropod community by

- Aims We investigated the effect of liming on the community structure of ground-hunting spiders in a birch forest.

- Methods We established six experimental birch stand plots. Each stand was exposed to one of three experimental treatments: control, $1.5 \mathrm{t} / \mathrm{ha}$, or $3 \mathrm{t} / \mathrm{ha}$ of dolomitic limestone. We collected spiders using pitfall traps during 5 years. We characterized the community in terms of activity density, species richness, community-weighted mean body size, and functional diversity and evenness in body size. We further investigated the potential links through which the liming might affect spiders, namely soil

- Results The commonly used dosage of 3 t/ha reduced densities of functionally similar species which led to the reduced functional evenness in body size and increased functional divergence in body size. Liming increased soil pH only slightly but

- Conclusion The liming affected the community of ground-hunting spiders, at least partially, through reduced densities of their

Electronic supplementary material The online version of this article (https://doi.org/10.1007/s13595-018-0769-8) contains supplementary material, which is available to authorized users.

Radek Michalko

radar.mi@seznam.cz

Emanuel Kula

emanuel.kula@mendelu.cz

Ondřej Košulič

Ondra.Kosulic@seznam.cz

1 Department of Forest Ecology, Faculty of Forestry and Wood Technology, Mendel University in Brno, Zemědělská 3, 613 00 Brno, Czech Republic

2 Department of Forest Protection and Wildlife Management, Faculty of Forestry and Wood Technology, Mendel University in Brno, Zemědělská 3, 61300 Brno, Czech Republic
Keywords Acidification $\cdot$ Functional diversity $\cdot$ Predator $\cdot$ Soil

\section{Introduction}

Liming is a method used to ameliorate highly acidified forest soils caused by acid rains across Europe and North America (Reid and Watmough 2014). Liming aims to enhance the availability of exchangeable calcium, neutralize the acidic inputs, and to enhance the buffering capacity of soil (Geissen et al. 1997). The increased soil $\mathrm{pH}$ enhances soil biological activity, litter decomposition and mineralization, and the release of nutrients that were trapped within the humus. The increased availability of $\mathrm{Ca}$ and released nutrients consequently enhance net primary productivity (Gradowski and Thomas 2008). In addition, liming reduces availability of potential toxic elements such as metal(loid)s (Geissen et al. 1997).

Lime application, however, remains controversial because not only positive effects but also no effect or negative effects have been observed (Reid and Watmough 2014). For example, high dosage of lime ( $\geq 9 \mathrm{t} / \mathrm{ha}$ ) can cause immediate rapid release of soil nutrients that are not taken up by vegetation. 
The soil nutrients can be then washed away (Klimo and Vavř́čck 1991). At the initial succession stages, liming can support shrubs that outcompete and retard the growth of the fostered tree species (Lin et al. 2015). Moreover, several endangered species are associated with the low soil $\mathrm{pH}$ and the increase of soil $\mathrm{pH}$ can harm them (Buckton and Ormerod 1997). The effect of liming therefore depends on the dosage, habitat, initial conditions, temporal scale, and taxa of interest (Reid and Watmough 2014).

All studies investigating the effect of liming on animal diversity explored the taxonomic diversity. No study so far has evaluated the effect of liming in terms of functional diversity. The functional approach that is accompanied by investigation of abiotic and biotic factors could help to better understand the mechanisms by which liming affects focal communities (Cadotte et al. 2011). The functional approach can also help to identify the functional traits that may be especially prone to liming. This might be useful for conservationists that could decide whether to apply liming in a given area depending on the presence of endangered species with such functional traits that could make them likely to disappear after lime application. In addition, the impact of liming on the functional composition of a focal community can help to predict further impacts on ecological dynamics (Rusch et al. 2015).

Functional diversity has several components that need to be investigated together to provide complete insight into the community structure (Mason et al. 2005). First is the community-weighted mean (CWM), which is the mean value of a trait in a community weighted by species' relative abundances (Lepš et al. 2006). Second is the functional diversity index (FD), which can be seen as a quantification of divergence in functional niche space among species in a community (de Bello et al. 2016). This may quantify the degree of niche differentiation and competition for resources (Mason et al. 2005). Third is the functional evenness (FEve), which can be seen as an estimation of the distribution the biomass of a community in functional niche space. This indicates how effective is the utilization of the entire range of available resources by the community (Mason et al. 2005).

Ground-hunting spiders provide an ideal model system for investigating the effect of liming on predator functional community structure. Firstly, ground-hunting spiders significantly influence the ecological processes in forests because they influence litter decomposition, mineralization, and productivity through trophic cascades (Strickland et al. 2013; Liu et al. 2015). The alteration of the functional structure in a spider community can consequently alter the functioning of the whole forest ecosystem (Strickland et al. 2013; Liu et al. 2015; Sanders et al. 2015). Secondly, spiders respond rapidly to the changes in environmental conditions such as canopy openness and litter structure, which can be influenced by liming (Isaia et al. 2015; Košulič et al. 2016; Lin et al. 2015). Thirdly, spiders are highly susceptible to the exposure of metal(oid)s, and their presence in an ecosystem can be reduced by liming (Geissen et al. 1997; Migula et al. 2013). Fourthly, ground-hunting spiders strongly respond to the availability of their preferred prey, which can also be affected by liming (Wise 1993; Chagnon et al. 2001). Spiders can increase their abundances in patches with high densities of their preferred prey through aggregative response and reproductive response (Tsutsui et al. 2016). Moreover, reduced prey availability can intensify intraguild predation (IGP) among spiders, which can lead to the exclusion of some species (Rickers et al. 2006).

The key functional trait in the ground-hunting spiders, which might determine the effect of liming on a spider species, is body size because it determines vulnerability to IGP (Rypstra and Samu 2005) and susceptibility to the metal(oid)s that accumulate with the increasing trophic level in a food chain (Migula et al. 2013). Thus, for example, more intense IGP can lead to the exclusion of small spider species (Rickers et al. 2006; Birkhofer et al. 2008). The changed body size distribution in a spider community can further alter the ecological dynamics and the outflow of prey biomass (Heckmann et al. 2012). This is because body size determines spiders' prey size, prey type, and per capita capture rate (Nentwig and Wissel 1986; Pekár et al. 2015; Sanders et al. 2015).

In this study, we explored how two dosages of liming, 1.5 and $3 \mathrm{t} / \mathrm{ha}$, affect community structure of ground-hunting spiders in a birch forest. We used 5-year time-series data gathered by collecting spiders using pitfall traps to obtain an exhaustive survey of species as rare species are the most vulnerable to local extinction due disturbances or negative interspecific interactions (Spiller and Schoener 1998; Davies et al. 2004). We characterized the community of ground-hunting spiders in terms of activity density, species richness, CWM in body size, and FD and FEve in body size. To explore the potential links through which the liming affects spiders, we investigated (1) soil characteristics, namely $\mathrm{pH}$, amount of $\mathrm{C}$ and $\mathrm{N}$, and $\mathrm{C} / \mathrm{N}$ ratio. (2) We investigated the effect of liming on growth of the fostered tree species, birch Betula pendula Roth (Betulaceae). We also investigated the amount of metal(oid)s in birch leaves as a proxy of metal(loid)s in the humus (i.e., the food source of spiders' prey). (3) We investigated the effect of liming on densities of several potential prey of ground-hunting spiders. We hypothesized that (1) the effect of liming on the community of ground-hunting spiders will increase with the dosage. But, we could not postulate any a priori hypothesis whether the effect will be positive or negative because various effects on spiders have been observed. We also hypothesized that liming will affect the ground-hunting spider (2) by altering the environmental conditions that influence spiders, such as canopy openness, which would decrease through enhanced tree growth. Or, (3) the liming will affect spiders prey resources, which might affect the spider community through bottom-up processes and/or through altered IG interactions. 


\section{Materials and methods}

\subsection{Studied area and liming application}

The experimental area is located in the Krušné Hory Mountains in the Czech Republic (50 $37^{\prime} 47^{\prime \prime} \mathrm{N}, 13^{\circ} 38^{\prime}$ $41^{\prime \prime} \mathrm{E}$ ). The study area is heavily polluted by metal(oid)s from nearby industrial centers. The soil type of the area is cambisol with gneissic subsoil. The whole study area was 10.2 ha. We established six experimental plots in the secondary birch forest stand during August 2003 (Fig. S1). As the plots were adjacent directly to each other and separated by $20-\mathrm{m}$ wide clearings (see Fig. S1 for the configuration of plots), they had similar tree composition, elevation, aspect, and slope (Table 1). The plots were then treated by air liming with granulated dolomitic limestone or left without liming as a control. Lime was applied only once in 2003. The liming dosages were 1.5 and $3 \mathrm{t} / \mathrm{ha}$. The dosage $3 \mathrm{t} / \mathrm{ha}$ is commonly used for liming (Šrámek et al. 2014). Each treatment had two spatial replicates. Obtaining more spatial replicates was logistically difficult because of financial limitations.

\subsection{Spider community}

We sampled the spider community in each plot from 2004 to 2008. We aimed to obtain two spatial and five temporal replicates of each treatment which would result in 30 samples. However, we obtained 27 samples as three samples had to be discarded ( 2 and 1 from 1.5 and $3 \mathrm{t} / \mathrm{ha}$, respectively) due to the flooding of some of the pitfall traps or damage caused by wild boars. We used temporal replicates for several reasons. The effect of liming is long-term and the effect can change with time (Lin et al. 2015).

In the middle of each plot, we installed a line of five sheltered pitfall traps (diameter $9 \mathrm{~cm}$; volume $4 \mathrm{l}$ ) situated at a regular interval of $10 \mathrm{~m}$. To eliminate edge effect, the peripheral traps were placed $10 \mathrm{~m}$ from the edges of the plot. We collected spiders from the guild of ground hunters (Cardoso et al. 2011), i.e., the families Lycosidae, Gnaphosidae, Zoridae, Dysderidae, Liocranidae, Phrurolithidae, and Dictynidae. During 2004-2008, the pitfall traps were operational from the beginning of May to the end of June and were emptied monthly. Overall, the traps were operational for 60 days in each year. We used 4\% formaldehyde and detergent as a preservation medium. We stored the collected samples in $75 \%$ ethanol. We identified the adult spiders under binocular stereomicroscope to species level using the key of Nentwig et al. (2016). The nomenclature follows the World Spider Catalog ver. 18.5 (WSC 2017). The material is deposited at Mendel University, Faculty of Forestry and Wood Technology in the collection of the second author.

We only collected spiders from the ground hunter guild, and only during May and June, because we wanted to minimize the confounding effects of other functional traits (other than body size), such as distinct hunting strategy, dispersal ability, and phenology. We collected the spiders during May and June because most of the ground-hunting spiders are adults during that time (Nentwig et al. 2016).

All analyses were performed within the $\mathrm{R}$ environment ( $\mathrm{R}$ Development Core Team 2016). We summed the five traps from each plot for statistical analyses and so a single sample was represented by the five pooled traps from a plot from 1 year. Overall, we obtained 27 samples (see above). To investigate the effect of liming on the community structure of ground-hunting spiders, we used activity density (no. of individuals/plot/60 days), species richness, and several indices that express different aspects of the functional structure of a community. The functional indices were CWM, FD, and functional evenness FEve (Mason et al. 2005; Lepš et al. 2006; de Bello et al. 2016). We used Euclidean distance as the distance measure.

The size of spiders was obtained from Nentwig et al. (2016) and is presented in Table 2. As we used the mean species size and did not measure the size of individuals (i.e., intraspecific variation), the changes in body size structure express the "composition shift," i.e., changes in relative abundances of differently sized species.

Species richness and FD are highly sensitive to differences in the number of collected individuals (Gotelli and Colwell 2001; Walker et al. 2008). We therefore rarefied the number of species and the FD to the size of the smallest sample $(N=41)$ and present the rarefied species richness and FD in all analyses. The rarefaction of FD is similar to the classical rarefaction but FD index is computed in each iteration (see Walker et al. 2008).

We used generalized least squares (GLS) to compare CWM and FEve among the treatments because they were normally distributed (Pekár and Brabec 2012). We used generalized estimating equations (GEE), which is an extension of generalized linear models for autocorrelated data with non-normal distribution (Pekár and Brabec 2012). We used GEE with Poisson structure and log link function (GEE-p) to investigate the effect of liming on the activity density because the response variable was counts (Pekár and Brabec 2016). Given that rarefied species richness and FD were continuous but non-normally distributed, we used GEE with gamma error structure and a log link function (GEE-g) to investigate the effect of liming (Pekár and Brabec 2012). In the GLSs and GEEs, the plots represented the statistical clusters, and we used autoregressive correlation structure because the measurements within the clusters were obtained in equal temporal intervals (Pekár and Brabec 2012). We treated the liming treatment as a discrete variable (i.e., factor) inasmuch as we had only three-point measurements (control, $1.5 \mathrm{t} / \mathrm{ha}$, and $3 \mathrm{t} / \mathrm{ha}$ ). To account for the between- 
Table 1 Characteristics of the sampling plots (see also Fig. S1)

\begin{tabular}{|c|c|c|c|c|c|c|c|c|c|c|}
\hline \multirow[t]{2}{*}{ Plots } & \multirow[t]{2}{*}{$\begin{array}{l}\text { Liming dosage } \\
(\mathrm{t} / \mathrm{ha})\end{array}$} & \multirow[t]{2}{*}{$\begin{array}{l}\text { Area } \\
\text { (ha) }\end{array}$} & \multirow[t]{2}{*}{$\begin{array}{l}\text { Elevation } \\
\text { (m a.s.1.) }\end{array}$} & \multirow[t]{2}{*}{ Aspect } & \multirow[t]{2}{*}{ Slope } & \multirow[t]{2}{*}{ Age } & \multicolumn{4}{|c|}{$\begin{array}{l}\text { Tree composition } \\
(\%)\end{array}$} \\
\hline & & & & & & & Betula & Fagus & Picea & Sorbus \\
\hline $1,2,3$ & $0,1.5,3$ & 1.3 & $710-730$ & South & Gentle & 20 & 65 & 5 & 10 & 20 \\
\hline $4,5,6$ & $0,1.5,3$ & 2 & $720-770$ & South & Middle & 27 & 80 & - & 5 & 15 \\
\hline
\end{tabular}

years differences, we also included year as a factor in the linear predictor but we do not interpret it because there was no clear temporal trend and it was not our aim to investigate how particular years affected the spider community. The initial models had the following structure:

Table 2 Mean activity densities (inds/plot) of ground-hunting spiders in a birch forest during 5 years and their size. Size was obtained from Nentwig et al. (2016)

\begin{tabular}{|c|c|c|}
\hline Family & Species & Size $(\mathrm{mm})$ \\
\hline Dictynidae & Cicurina cicur (Fabricius 1793) & 6 \\
\hline Dysderidae & Harpactea lepida (CL Koch 1838) & 6 \\
\hline \multirow[t]{14}{*}{ Gnaphosidae } & Callilepis nocturna (Linnaeus 1758) & 5 \\
\hline & Drassodes cupreus (Blackwall 1834) & 13.5 \\
\hline & Drassodes pubescens (Thorell 1856) & 7.5 \\
\hline & Drassyllus praeficus (L Koch 1866) & 6.5 \\
\hline & Gnaphosa montana (L Koch 1866) & 11.5 \\
\hline & Haplodrassus signifier (CL Koch 1839) & 8 \\
\hline & Haplodrassus silvestris (Blackwall 1833) & 8.5 \\
\hline & Micaria pulicaria (Sundevall 1831) & 3.75 \\
\hline & Trachyzelotes pedestris (CL Koch 1837) & 6.5 \\
\hline & Zelotes clivicola (L Koch 1870) & 5 \\
\hline & Zelotes electus (CL Koch 1839) & 4.5 \\
\hline & Zelotes latreillei (Simon 1878) & 7 \\
\hline & Zelotes petrensis (CL Koch 1839) & 6.5 \\
\hline & Zelotes subterraneus (CL Koch 1833) & 7 \\
\hline Liocranidae & Agroeca brunnea (Blackwall 1833) & 7.5 \\
\hline \multirow[t]{8}{*}{ Lycosidae } & Alopecosa pulverulenta (Clerck 1757) & 8 \\
\hline & Alopecosa taeniata (CL Koch 1835) & 11.5 \\
\hline & Pardosa lugubris (Walckenaer 1802) & 6.5 \\
\hline & Pardosa pullata (Clerck 1757) & 5 \\
\hline & Pardosa riparia (CL Koch 1833) & 5 \\
\hline & Pardosa saltans Topfer-Hofmann 2000 & 6 \\
\hline & Trochosa terricola Thorell 1856 & 11 \\
\hline & Xerolycosa nemoralis (Westring 1861) & 6 \\
\hline Phrurolithidae & Phrurolithus festivus (CL Koch 1835) & 2.75 \\
\hline \multirow[t]{3}{*}{ Zoridae } & Zora nemoralis (Blackwall 1861) & 4.5 \\
\hline & Zora silvestris Kulczyński 1897 & 3.5 \\
\hline & Zora spinimana (Sundevall 1833) & 6.25 \\
\hline
\end{tabular}

$$
\begin{aligned}
& y_{i j k}=\alpha+\text { treatment }_{j}+\operatorname{year}_{k}+\varepsilon_{i j k} \\
& \varepsilon_{i j k}=\varphi \varepsilon_{j k, i-1}+v_{i j k} ; v_{i j k} \sim N\left(0, \sigma_{v}^{2}\right), \operatorname{cor}\left(v_{i j k}, v_{i^{\prime} j^{\prime} k^{\prime}}\right)=0 \text { if } i j k \neq i^{\prime} j^{\prime} k^{\prime}
\end{aligned}
$$

or

$\log \left(\mu_{i j k}\right) \sim \alpha+$ treatment $_{j}+$ year $_{k}$

activity density $\operatorname{ijk}_{i j} \sim \operatorname{Poisson}\left(\mu_{i j k}\right)$

$\operatorname{species} \operatorname{richness}_{i j k} \sim \operatorname{Gamma}\left(\mu_{i j k}, \varphi\right)$

$F D_{i j k} \sim \operatorname{Gamma}\left(\mu_{i j k}, \varphi\right)$

$\mathrm{AR}(1)$ correlation matrix of the true residuals of each plot

In the model Formula (1), $y$ represents either CWM or FEve. The terms were removed by backward selection according to their significance and the rule of marginality (Pekár and Brabec 2016).

We used kernel density estimation to visualize the size distribution in the control treatment and in the liming dosage of 3 tha.

\subsection{Soil characteristics}

To evaluate whether the liming affected the soil characteristics, which could potentially influence the ecological dynamic, we sampled the forest floor and soil (i.e., the humus and organic matter horizons, $3-4 \mathrm{~cm}$ ). We performed three pedologic samples in each plot and each year. The samples were situated along the transects of the pitfall traps with $20 \mathrm{~m}$ distance from the transects. The three samples were homogenized into one sample from which we obtained the soil characteristics in the laboratory.

Values of active $\left(\mathrm{pH} \mathrm{H}_{2} \mathrm{O}\right)$ and exchangeable $(\mathrm{pH} \mathrm{KCl})$ soil acidity was determined by potentiometry using a digital $\mathrm{pH}$ meter (Zbíral 1995). From air-dried soil samples free of coarse particles, total nitrogen and carbon were determined after fine grinding or comminution (Zbíral et al. 1997).

Due to computational errors, we analyzed the two soil horizons separately, but we used the Bonferroni correction of $P$ values. We used GLSs and GEE-gs for normally and non- 
normally distributed data, respectively (Table 2 ). The initial models were the same as Eq. (1) for GLS and Eq. (2) for GEE-g.

\subsection{Birch tree characteristics}

As ground-hunting spiders react to canopy openness (Isaia et al. 2015), we compared growth of birch trees among the treatments. We also investigated the presence of metal(oid)s $(\mathrm{Al}, \mathrm{Cd}, \mathrm{Cu}, \mathrm{Pb}, \mathrm{Mn}, \mathrm{Zn})$ in birch leaves, which highly corresponds with the amount of metal(oid)s in the soil (Bergmann 1988).

To measure tree growth, we selected 25 permanent birch trees in each plot along the transect of the pitfall traps $(N=$ 150). We measured the tree width each year at the beginning of vegetation season during 2004-2008.

We selected three permanent trees out of the 25 trees for evaluation of the leaves' chemistry in each plot $(N=18)$. We collected the leaves to investigate the amount of metal(oid)s according to the methodology UN-ECE (1998) at the end of August each year. The amount of metal(oid)s from dried leaves were performed by the specialized laboratory Laboratoř Morava s.r.o. (EKOLA 2008).

We used GLS to compare the amount of metal(oid)s among the treatments. The initial models were similar as Eq. (1). In the exploratory analyses, the trees seemed to grow asymptotically during the period 2004-2008. We therefore compared the tree growth with GEE-g with inverse link. The variable year was treated as a continuous variable (i.e., covariate) and it was inversely transformed to fit the asymptotic relationship (Pekár and Brabec 2016). We included the interaction between year and treatment. The linear predictor was of ANCOVA type and the terms were excluded according to their significance and the rule of marginality (Pekár and Brabec 2016). The initial model was as follows:

$\frac{1}{\mu_{i j}}=\alpha+$ treatment $_{j}+\beta \frac{1}{\text { year }_{i}}+\gamma_{j} \frac{1}{\text { year }_{i}}$ $\operatorname{growth}_{i j} \sim \operatorname{Gamma}\left(\mu_{i j}, \varphi\right)$

$\mathrm{AR}(1)$ correlation matrix of the true residuals of each plot

\subsection{Potential prey}

We investigated whether the liming can affect potential prey of the ground-hunting spiders and consequently also the spider community via bottom-up processes. We investigated abundances of the following groups that represent the main part of ground-hunting spiders' diet: Collembola, Sternorrhyncha, Auchenorrhyncha,
Heteroptera, Coleoptera, Lepidoptera, Diptera, and Hymenoptera (Michalko and Pekár 2016). However, we obtained only one spatial replicate per each dosage of liming and control (plots: 4, 5, 6; Table 1; Fig. S1). We collected the potential prey by ground photoeclectors (area $0.5 \mathrm{~m}^{2}$; size $0.5 \times 1.0 \times 0.3 \mathrm{~m}$ ) from 2004 to 2008 . Each year, three photoeclectors were installed on each plot from the beginning of March until the end of October. Except 2006, when the photoeclectors were installed later, at the beginning of April, because of the presence of snow cover. The photoeclectors were checked in regular fortnight intervals. The samples from the three photoeclectors were pooled across the whole season. Altogether, we obtained five temporal replicates of each treatment resulting in 15 samples.

We compared the abundances of the potential prey among the treatments by the negative binomial GLMs (GLM-nb) with a $\log$ link because the data were counts and overdispersed (Pekár and Brabec 2016). To account for variation among years, we added the effect of year in the linear predictors. We treated year as a discrete variable because the trend can be non-linear and because of the difference in the deposition time of the photoeclectors among years. The initial models had the following structure:

$$
\begin{aligned}
& \log \left(\mu_{j k}\right)=\alpha+\text { treatment }_{j}+\text { year }_{k}, \\
& \text { abundance }_{j k} \sim N B\left(\mu_{j k}, \theta\right)
\end{aligned}
$$

\section{Results}

\subsection{Effect of liming on spider community}

We collected 2769 adult individuals of ground-hunting spiders belonging to 29 species (Table 2). The community was largely dominated by four species: Pardosa lugubris (Walckenaer 1802) (48\%), Harpactea lepida (CL Koch 1838) (19\%), Trochosa terricola Thorell 1856 (17\%), and Zelotes subterraneus (CL Koch 1833) (6\%).

Species richness and activity density significantly decreased with liming dosage $(P<0.006$; Table 3, Fig. 1a, b). The control had higher species richness and higher activity density of spiders than did the $3 \mathrm{t} / \mathrm{ha}$ dosage (contrasts, $P<0.005)$. The control and $1.5 \mathrm{t} / \mathrm{ha}$ dosage did not differ significantly (contrasts, $P>0.464$ ).

Liming had no significant effect on CWM or FD $(P>0.750$; Table 3$)$. However, liming treatment significantly influenced FEve $(P=0.006$; Table 3, Fig. 1c). The control had higher FEve than the 3 t/ha dosage did (contrasts, $P=0.014$ ). The control and $1.5 \mathrm{t} / \mathrm{ha}$ 
Table 3 The results of the effect of liming on spider communities, soil characteristics, birch trees, and the spiders' potential prey. The significant $P$ values are in bold. The upper index B means that the $P$ value was adjusted by Bonferroni correction

\begin{tabular}{|c|c|c|c|c|}
\hline & Dependent variable & Method & Test statistic & $P$ value \\
\hline \multirow[t]{7}{*}{ Spider community } & Species richness & GEE-g & $\chi_{2}^{2}=10.3$ & 0.006 \\
\hline & Activity density & GEE-p & $\chi_{2}^{2}=89.8$ & $<0.001$ \\
\hline & CWM & GLS & $F_{2,24}<0.1$ & 0.928 \\
\hline & FD & GEE-g & $\chi_{2}^{2}=0.5$ & 0.768 \\
\hline & FEve & GLS & $F_{2,24}=6.0$ & 0.006 \\
\hline & $\mathrm{pH}\left(\mathrm{H}_{2} \mathrm{O}\right)$ - humus horizon & GEE-g & $\chi_{2}^{2}=282.4$ & $<0.001^{\mathrm{B}}$ \\
\hline & $\mathrm{pH}\left(\mathrm{H}_{2} \mathrm{O}\right)$ - organic-mineral horizon & GEE-g & $\chi_{2}^{2}=3.2$ & 0.202 \\
\hline \multirow[t]{10}{*}{ Soil characteristics } & $\mathrm{pH}(\mathrm{KCl})$ - humus horizon & GEE-g & $\chi_{2}^{2}=644.0$ & $<0.001^{\mathrm{B}}$ \\
\hline & $\mathrm{pH}(\mathrm{KCl})$ - organic-mineral horizon & GEE-g & $\chi_{2}^{2}<0.1$ & 0.936 \\
\hline & $\mathrm{C}$ - humus horizon & GLS & $F_{2,23}<0.1$ & 0.683 \\
\hline & $\mathrm{C}$ - organic-mineral horizon & GEE-g & $\chi_{2}^{2} 4.0$ & 0.130 \\
\hline & $\mathrm{N}$-humus horizon & GLS & $F_{2,23}<0.1$ & 0.758 \\
\hline & $\mathrm{N}$-organic-mineral horizon & GEE-g & $\chi_{2}^{2} 0.7$ & 0.710 \\
\hline & $\mathrm{C} / \mathrm{N}-$ humus horizon & GLS & $F_{2,23}=1.0$ & 0.376 \\
\hline & $\mathrm{C} / \mathrm{N}$ - organic-mineral horizon & GLS & $F_{2,23}=1.0$ & 0.466 \\
\hline & Sulfur-humus horizon & GLS & $F_{2,23}<0.1$ & 0.923 \\
\hline & Aluminum & GLS & $F_{2,23}=0.1$ & 0.880 \\
\hline \multirow[t]{6}{*}{ Birch tree } & Cadmium & GLS & $F_{2,23}=0.3$ & 0.758 \\
\hline & Copper & GLS & $F_{2,23}=2.8$ & 0.085 \\
\hline & Lead & GLS & $F_{2,23}=0.2$ & 0.816 \\
\hline & Mangan & GLS & $F_{2,23}=0.6$ & 0.545 \\
\hline & Zinc & GLS & $F_{2,23}<0.1$ & 0.968 \\
\hline & Growth rate & GEE-g & $\chi_{2}^{2}=0.4$ & 0.818 \\
\hline \multirow[t]{9}{*}{ Potential prey } & Overall & GLM-nb & $\chi_{2}^{2}=4.6$ & 0.100 \\
\hline & Collembola & GLM-nb & $\chi_{2}^{2}=4.8$ & 0.089 \\
\hline & Sternorrhyncha & GLM-nb & $\chi_{2}^{2}=12.7$ & 0.001 \\
\hline & Auchenorrhyncha & GLM-nb & $\chi_{2}^{2}=4.6$ & 0.102 \\
\hline & Heteroptera & GLM-nb & $\chi_{2}^{2}=21.6$ & $<0.001$ \\
\hline & Coleoptera & GLM-nb & $\chi_{2}^{2}=8.7$ & 0.013 \\
\hline & Lepidoptera & GLM-nb & $\chi_{2}^{2}=9.0$ & 0.011 \\
\hline & Diptera & GLM-nb & $\chi_{2}^{2}=6.0$ & 0.049 \\
\hline & Hymenoptera & GLM-nb & $\chi_{2}^{2}=0.9$ & 0.624 \\
\hline
\end{tabular}

dosage did not differ significantly (contrasts, $P=0.350$ ). The size distribution in the control and at $3 \mathrm{t} / \mathrm{ha}$ dosage is illustrated in Fig. 1d. The broader distribution of the body size remained similar because two distinct size classes could be distinguished in both treatments. However, the smaller size class was broken into several narrow steep peaks while the larger size class was narrowed to one steep peak in the treatment $3 \mathrm{t} / \mathrm{ha}$ in comparison to control. Therefore, the distribution of body size at the liming dosage of $3 \mathrm{t} / \mathrm{ha}$ is less regular and more divergent than the distribution in the control treatment. The liming therefore did not create a directed selection for certain body size. Instead, liming reduced densities of functionally similar or "adjacent" species.

\subsection{Effect of liming on the soil characteristics}

In the humus horizon, soil active $\mathrm{pH}$ as well as exchangeable $\mathrm{pH}$ significantly increased with the dosage of lime $\left(P_{\text {Bonferroni }}\right.$ $<0.001$; Table 3, Fig. 2). The soil's active $\mathrm{pH}$ or exchangeable $\mathrm{pH}$ in the organic-mineral horizon did not differ among the liming treatments $(P=0.936)$. The amount of $\mathrm{C}, \mathrm{N}$, and $\mathrm{C} / \mathrm{N}$ ratio did not differ among the treatments in any soil horizon $(P>0.375$; Table 2).

\subsection{Effect of liming on birch}

The birch growth $(P=0.818$; Table 2$)$ did not differ among the liming treatments significantly. Liming did not 
Fig. 1 Community structure of ground-hunting spiders in birch forest dependent on liming dosage. The community structure was explored with respect to species richness (a), activity density (b), and functional evenness in body size (c). The points are means and the segment lines are standard errors (SE). Panel (d) shows body size distribution in communities of ground-hunting spiders in control plots and plots limed with the $3 \mathrm{t} /$ ha dosage. The results are based on data collected during 2004 2008
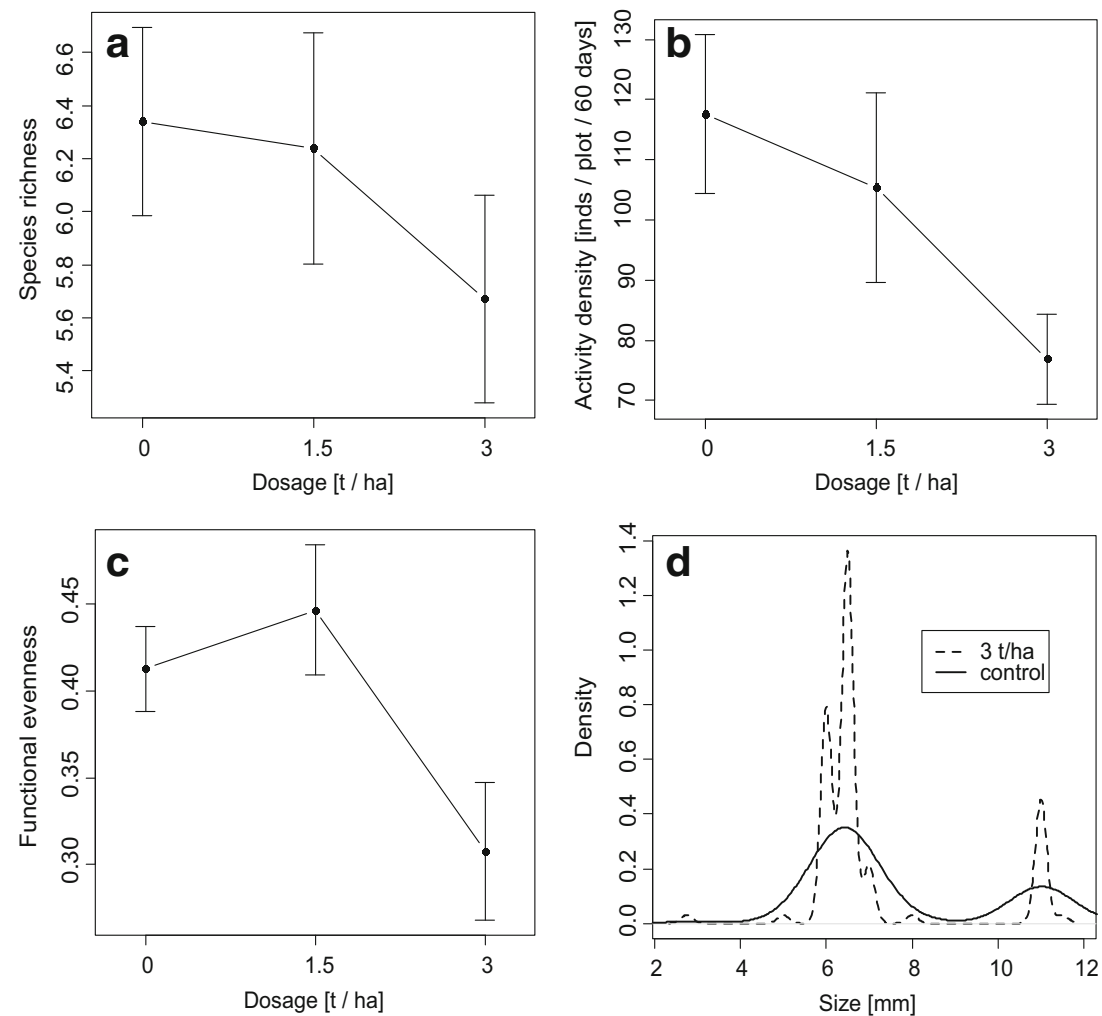

significantly affect the amount of any of the investigated metal(oid)s in birch $(P>0.084$, Table 3$)$.

\subsection{Effect of liming on composition of potential prey of spiders}

The overall prey availability, abundances of Collembola, Auchenorrhyncha, and Hymenoptera did not differ significantly among the plots $(P>0.088$, Table 3$)$. The abundances of Diptera and Coleoptera significantly decreased with increasing dosage of lime $(P<0.05$; Table 3, Fig. 3a, b).

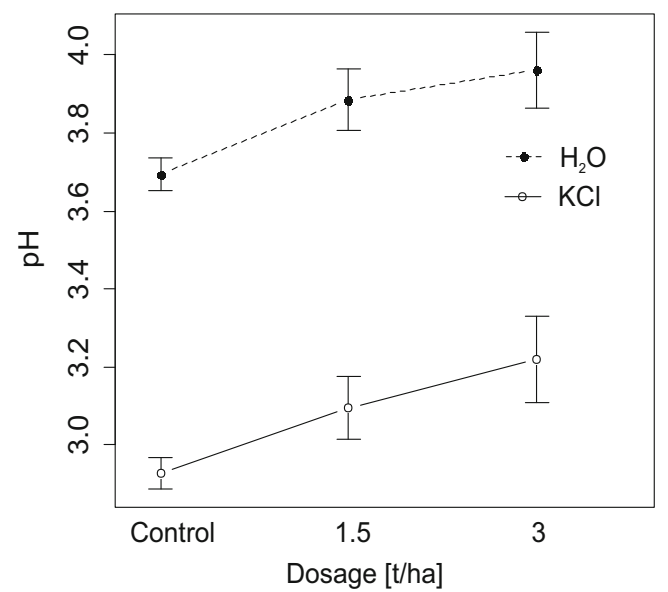

Fig. 2 Comparison of soil $\mathrm{pH}$ among plots treated with different liming dosage. The points are means and the segment lines are SE. The results are based on data collected during 2004-2008
Abundance of Lepidoptera and Heteroptera increased with the dosage of lime $(P<0.012$; Table 3, Fig. 3c, d). Abundance of Sternorrhyncha differed significantly among the plots $(P=0.001$; Table 3, Fig. 3e). Sternorrhyncha were more abundant in the plot treated by $1.5 \mathrm{t} / \mathrm{ha}$ of limestone than in the control plot (contrasts, $P=0.011$ ) but in the plot treated by $3 \mathrm{t} / \mathrm{a}$ of limestone they were marginally less abundant than in the control plot (contrasts, $P=0.053$ ).

\section{Discussion}

In the current study, we investigated the effect of liming on community structure of ground-hunting spiders, namely species richness, activity density, community-weighted mean body size, functional diversity in body size, and functional evenness in body size. Although there was no significant effect of the $1.5 \mathrm{t} / \mathrm{ha}$ liming dosage, the $3 \mathrm{t} / \mathrm{ha}$ dosage significantly reduced species richness, activity densities, and functional evenness of ground-hunting spiders. FD and CWM were not significantly affected. FD depends on species richness as well as functional divergence, and so the same FD with lower species richness means that the increased trait divergence compensated for the species loss (Lepš et al. 2006). The changes in community structure were caused by reduced densities of functionally similar species. The negative impact of liming on ground-hunting spiders is in agreement with other studies on lycosid spiders (Buckton and Ormerod 1997) or 
Fig. 3 Comparison of abundances of Diptera (a), Coleoptera (b), Lepidoptera (c), Heteroptera (d), and Sternorrhyncha (e) among plots treated with different liming dosage. The points are means and the segment lines are SE. The results are based on data collected during 2004-2008

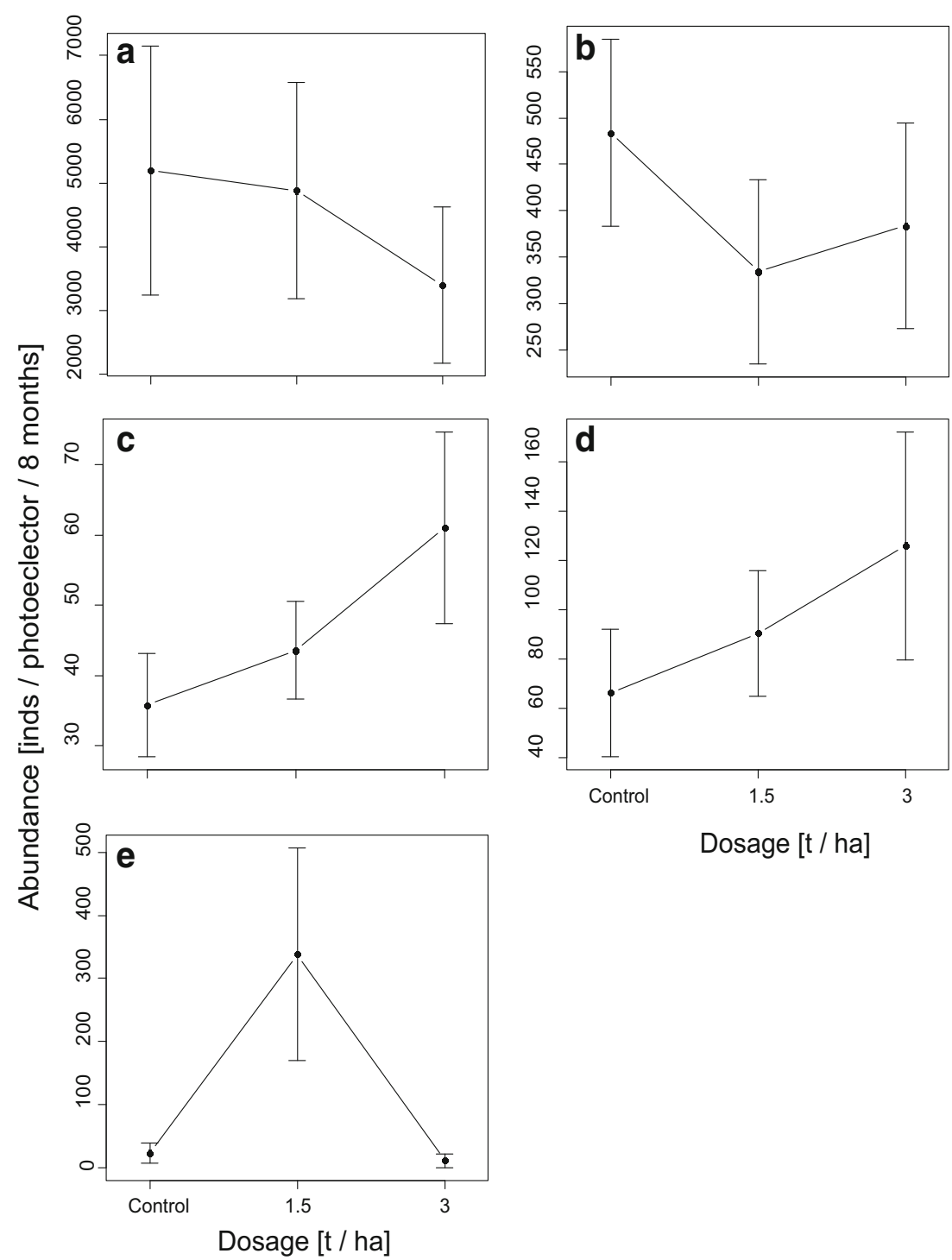

spiders generally (McCay et al. 2013). Positive or no effects have also been reported, however, for example on linyphiids (Buckton and Ormerod 1997) and spiders in general (Korenko et al. 2008). It nevertheless should be noted that what was observed in the present study is a short-time effect (5 years) and the effect can change with time (Lin et al. 2015). Consequently, an opposite effect might be observed in the future.

Liming increased the $\mathrm{pH}$ of soil but had no effect on other studied characteristics. Liming had no significant effect on the observed birch tree characteristics. Although the soil $\mathrm{pH}$ increased with the dosage of lime, the increase was too small to significantly affect the soil fauna. However, lime is a source of $\mathrm{CO}_{2}$ when it reacts with an acid soil. $\mathrm{CO}_{2}$ then acts as a special salt content or electrolyte, which causes that the soil $\mathrm{pH}$ does not fully neutralize until this $\mathrm{CO}_{2}$ diffuses out of the soil (McLean 1982). The increased concentration of $\mathrm{CO}_{2}$ in soil might theoretically reduce the densities of soil fauna through hypercarbia (Zinkler and Platthaus 1996; Haimi et al. 2005; $\mathrm{Xu}$ et al. 2013). But, the exact reason for the lowered densities of spiders' prey is unknown.

Although there was no significant effect of liming on the overall prey abundances, the $3 \mathrm{t} / \mathrm{h}$ a liming dosage significantly reduced densities of Diptera, Sternorrhyncha, and Coleoptera which represent a substantial part of the ground-hunting spiders' diet (Michalko and Pekár 2016). The opposite pattern was observed for Lepidoptera and Heteroptera; however, they represent only a minor part of the ground-hunting spiders' diet (Michalko and Pekár 2016). Our results indicate that the liming affected the ground-hunting spiders, to some extent, indirectly through their prey.

The reduced availability of the preferred prey in the limed plots could affect the spider community in two, non-exclusive, ways. Firstly, reduced prey availability could lead to the emigration of spiders because spiders are known to aggregate in patches with higher densities of prey (Harwood et al. 2003). 
Secondly, the reduced availability of preferred prey could intensify the negative intraguild interactions (Rickers et al. 2006). The later explanation is supported by the differences in body size distribution between the treatments. Liming led to the reduced densities, or the exclusion, of the functionally similar species (Fig. 1d). The coexistence in IGP systems is enhanced via some form of niche partitioning (Amarasekare 2007).

Given the strong influence spiders have on ecosystem functioning (Strickland et al. 2013; Liu et al. 2016), an altered community size structure of a spider community, due to liming, could further alter the functioning of the whole ecosystem through trophic cascades by allocation of predation pressure. The reduced FEve and increased functional divergence may cause some prey sizes to be exposed to lower predation pressure than others (Mason et al. 2005).

It must be noted that the change in community structure may be caused not only by mortality and emigration but also by the change in locomotor activity because the pitfall trapping only shows activity densities instead of absolute abundances (Saska et al. 2013). Nevertheless, the change in locomotor activity would mean that the size is re-distributed between relatively sedentary and mobile hunting strategies. Even such small changes in the mobility of their hunting strategy, i.e., at an intraspecific level or among closely related spider species, can affect the food-web dynamics by altering predator-prey interactions (Miller et al. 2014; Royauté and Pruitt 2015).

In conclusion, our results show that the commonly used dosage of $3 \mathrm{t} / \mathrm{ha}$ reduced densities of functionally similar species of ground-hunting spiders. This led to the reduced functional evenness in body size and increased functional divergence in body size. The liming affected spiders indirectly through reduced densities of their preferred prey. As the liming did not improve any of the investigated characteristics of the fostered birch trees, and it had mostly negative or no effect on the arthropod communities, the usage of liming, even at relatively low dosages, is highly questionable. Nevertheless, we investigated only the short-term effects and it is possible that the long-term effects might still be positive (Lin et al. 2015).

Acknowledgments We would like to thank Stano Korenko, Lenka Sentenská, and Eva Líznarová for their help with the spider determination. We are grateful to Marco Isaia, the editors Aurélien Sallé and Erwin Dreyer, and the anonymous reviewers for their very helpful comments on the previous version of the manuscript.

Funding This study was financially supported by the Internal Grant Agency of Mendel University (Reg. No. LDF_VT 2016002/2016) and by Netex Ltd., Děčín, Nadace ČEZ Co. in Prague, and Lafarge Cement Co. in Čížkovice.

Statement on data availability The datasets generated during and/or analyzed during the current study are available in the supplementary material Table S1.

\section{Compliance with ethical standards}

Conflict of interest The authors declare that they have no conflict of interest.

\section{References}

Amarasekare P (2007) Trade-offs, temporal variation, and species coexistence in communities with intraguild predation. Ecology 88:2720 2728

Bergmann W (1988) Ernährungsstörungen bei Kulturplanzen. G. Fischer Verlag, Jena

Birkhofer K, Fließbach A, Wise DH, Scheu S (2008) Generalist predators in organically and conventionally managed grass-clover fields: implications for conservation biological control. Ann Appl Biol 153: 271-280

Buckton ST, Ormerod SJ (1997) Effects of liming on the Coleoptera, Hemiptera, Araneae and Opiliones of catchment wetlands in Wales. Biol Conserv 79:43-57

Cadotte MW, Carscadden K, Mirotchnick N (2011) Beyond species: functional diversity and the maintenance of ecological processes and services. J Appl Ecol 48:1079-1087

Cardoso P, Pekár S, Jocqué R, Coddington JA (2011) Global patterns of guild composition and functional diversity of spiders. PLoS One 6: e21710

Chagnon M, Paré D, Hébert C, Camiré C (2001) Effects of experimental liming on collembolan communities and soil microbial biomass in a southern Quebec sugar maple (Acer saccharum Marsh.) stand. Appl Soil Ecol 17:81-90

Davies KF, Margules CR, Lawrence JF (2004) A synergistic effect puts rare, specialized species at greater risk of extinction. Ecology 85: 265-271

de Bello F, Carmona CP, Lepš J, Szava-Kovats R, Pärtel M (2016) Functional diversity through the mean trait dissimilarity: resolving shortcomings with existing paradigms and algorithms. Oecologia 180:933-940

Ekola (2008) Inner laboratory methods

Geissen V, Illmann J, Flohr A, Kahrer R, Brümmer GW (1997) Effects of liming and fertilization on Collembola in forest soils in relation to soil chemical parameters. Pedobiologia 41:194-201

Gotelli NJ, Colwell RK (2001) Quantifying biodiversity: procedures and pitfalls in the measurement and comparison of species richness. Ecol Lett 4:379-391

Gradowski T, Thomas SC (2008) Responses of Acer saccharum canopy trees and saplings to $\mathrm{P}, \mathrm{K}$ and lime additions under high $\mathrm{N}$ deposition. Tree Physiol 28:173-185

Haimi J, Laamanen J, Penttinen R, Räty M, Koponen S, Kellomäki S, Niemelä P (2005) Impacts of elevated $\mathrm{CO}_{2}$ and temperature on the soil fauna of boreal forests. Appl Soil Ecol 30:104-112

Harwood JD, Sunderland KH, Symondson WOC (2003) Web-location by linyphiid spiders: prey-specific aggregation and foraging strategies. J Anim Ecol 72:745-756

Heckmann L, Drossel B, Brose U, Guill C (2012) Interactive effects of body-size structure and adaptive foraging on food-web stability. Ecol Lett 15:243-250

Isaia M, Paschetta M, Gobbi M, Zapparoli M, Chiarle A, Taglianti AV (2015) Stand maturity affects positively ground-dwelling arthropods in a protected beech forest. Ann For Sci 72:415-424

Klimo E, Vavříček D (1991) Acidifikace a vápnění lesních půd v Beskydech. Lesnictví 37:61-72

Korenko S, Kula E, Holec M, Jarab M, Michalková V (2008) Influence of liming on the epigeic spider (Araneae) community of the Krušné hory Mts.(Czech Republic). Eur J Soil Biol 44:559-566 
Košulič O, Michalko R, Hula V (2016) Impact of canopy openness on spider communities: implications for conservation management of formerly coppiced oak forests. PLoS One 11:e0148585

Lepš J, de Bello F, Lavorel S, Berman S (2006) Quantifying and interpreting functional diversity of natural communities: practical considerations matter. Preslia 78:481-501

Lin N, Bartsch N, Heinrichs S, Vor T (2015) Long-term effects of canopy opening and liming on leaf litter production, and on leaf litter and fine-root decomposition in a European beech (Fagus sylvatica L.) forest. For Ecol Manag 338:183-190

Liu S, Chen J, Gan W, Schaefer D, Gan J, Yang X (2015) Spider foraging strategy affects trophic cascades under natural and drought conditions. Sci Rep 5:12396

Mason NW, Mouillot D, Lee WG, Wilson JB (2005) Functional richness, functional evenness and functional divergence: the primary components of functional diversity. Oikos 111:112-118

McCay TS, Cardelús CL, Neatrour MA (2013) Rate of litter decay and litter macroinvertebrates in limed and unlimed forests of the Adirondack Mountains, USA. For Ecol Manag 304:254-260

McLean EO (1982) Soil pH and lime requirement. In: Page AL, Miller RH, Keeney DR (eds) Methods of soil analysis. Part 2. Chemical and microbiological properties, pp 199-224

Michalko R, Pekár S (2016) Different hunting strategies of generalist predators result in functional differences. Oecologia 181:1187-1197

Migula P, Wilczek G, Babczyńska A (2013) Effects of heavy metal contamination. In: Nentwig W (ed) Spider ecophysiology. Springer, Berlin, pp 403-414

Miller JR, Ament JM, Schmitz OJ (2014) Fear on the move: predator hunting mode predicts variation in prey mortality and plasticity in prey spatial response. J Anim Ecol 83:214-222

Nentwig W, Wissel C (1986) A comparison of prey lengths among spiders. Oecologia 68:595-600

Nentwig W, Hanngi A, Kropf C, Blick T (2016) Central European Spiders. An internet identification key. http://www.araneae.unibe. $\mathrm{ch} /$. Accessed 2 June 2016

Pekár S, Brabec M (2012) Modern analysis of biological data. 2. Linear models with correlation in R. MUNI Press, Brno

Pekár S, Michalko R, Loverre P, Líznarová E, Černecká L' (2015) Biological control in winter: novel evidence for the importance of generalist predators. J Appl Ecol 52:270-279

Pekár S, Brabec M (2016) Modern analysis of biological data. 1. Generalized linear models in R. Scientia

R Development Core Team (2016) R. A language and environment for statistical computing. R foundation for statistical computing, Vienna Available: http://www.R-project.org/. Accessed 2 June 2016

Reid C, Watmough SA (2014) Evaluating the effects of liming and woodash treatment on forest ecosystems through systematic meta-analysis. Can J For Res 44:867-885

Rickers S, Langel R, Scheu S (2006) Stable isotope analyses document intraguild predation in wolf spiders (Araneae: Lycosidae) and underline beneficial effects of alternative prey and microhabitat structure on intraguild prey survival. Oikos 114:471-478

Royauté R, Pruitt JN (2015) Varying predator personalities generates contrasting prey communities in an agroecosystem. Ecology 96: 2902-2911

Rusch A, Birkhofer K, Bommarco R, Smith HG, Ekbom B (2015) Predator body sizes and habitat preferences predict predation rates in an agroecosystem. Basic Appl Ecol 16:250-259

Rypstra AL, Samu F (2005) Size dependent intraguild predation and cannibalism in coexisting wolf spiders (Araneae Lycosidae). J Arachnol 33:390-397

Sanders D, Vogel E, Knop E (2015) Individual and species-specific traits explain niche size and functional role in spiders as generalist predators. J Anim Ecol 84:134-142

Saska P, van der Werf W, Hemerik L, Luff ML, Hatten TD, Honek A (2013) Temperature effects on pitfall catches of epigeal arthropods: a model and method for bias correction. J Appl Ecol 50:181-189

Spiller DA, Schoener TW (1998) Lizards reduce spider species richness by excluding rare species. Ecology 79:503-516

Šrámek V, Novotný R, Fiala P, Neudertová-Hellebrandová K, Reininger D, Samek T, Čihák T, Fadrhonsová V (2014) Forest liming in the Czech Republic. Czech Republic, Ministry of Agriculture http:// www.vulhm.cz/sites/files/soubory/23_ekologie_lesa/kniha_ Vapneni lesu.pdf

Strickland MS, Hawlena D, Reese A, Bradford MA, Schmitz OJ (2013) Trophic cascade alters ecosystem carbon exchange. PNAS 110: 11035-11038

Tsutsui MH, Tanaka K, Baba YG, Miyashita T (2016) Spatio-temporal dynamics of generalist predators (Tetragnatha spider) in environmentally friendly paddy fields. Appl Entomol Zool 51:631-640

UN-ECE (1998) Manual on methods and criteria for harmonized sampling, assessment, monitoring and analysis of the effects of air pollution on forests. Hamburg. www.icp-forests.org/reports.htm. Accessed 11. 11. 2006

Walker SC, Poos MS, Jackson DA (2008) Functional rarefaction: estimating functional diversity from field data. Oikos 117:286-296

Wise DH (1993) Spiders in ecological webs. Cambridge

World Spider Catalog (2017) World spider catalog. Natural History Museum, Bern online at http://wsc.nmbe.ch, version 18.5, accessed on 26.8.2017. doi: 10.24436/2

Xu GL, Fu SL, Schleppi P, Li MH (2013) Responses of soil Collembola to long-term atmospheric $\mathrm{CO}_{2}$ enrichment in a mature temperate forest. Environ Pollut 173:23-28

Zbíral J (1995) Soil analysis I. ÚKZÚZ, Brno. (in Czech)

Zbíral J, Honsa I, Malý S (1997) Soil analysis III. ÚKZÚZ, Brno. (in Czech)

Zinkler D, Platthaus J (1996) Tolerance of soil-dwelling Collembola to high carbon dioxide concentrations. Eur J Entomol 93:443-450 